\title{
An International Carbon-Price Commitment Promotes Cooperation
}

\author{
PETER CRAMTON ${ }^{\mathrm{a}}$ AXEL OCKENFELS,${ }^{\mathrm{b}}$ and STEVEN STOFT ${ }^{\mathrm{c}}$
}

\begin{abstract}
To promote cooperation in international climate negotiations, negotiators should focus on a common commitment. Such commitments have the advantage of facilitating reciprocal "I will if you will" agreements in a group. Reciprocity is the basis for cooperation in repeated public goods games, and a uniform price would provide a natural focal point for a common international commitment. Such a price is also essential for efficient abatement. Countries would retain flexibility in bow to implement the price-with cap-and-trade, a carbon tax, or a bybrid approach. Country risk is reduced relative to risk under international cap-and-trade since carbon revenues stay within the country. Price commitments also tend to equalize effort intensity and can facilitate enforcement. To encourage participation by less-developed countries, a green fund is needed to transfer money from richer to poorer countries. Transfers are smaller and more predictable with a uniform price commitment than with international cap and trade.
\end{abstract}

Keywords: Climate change, global warming, carbon pricing, international public goods, UN climate negotiations, prices versus quantities

http://dx.doi.org/10.5547/2160-5890.4.2.aock

\section{* HOW A COMMON COMMITMENT PROMOTES INTERNATIONAL AGREEMENT}

For twenty years, climate negotiators have been stymied by the most challenging tragedy of the commons ever encountered. The central problem is well understood. All countries can use the atmospheric commons for free, but only a small fraction of the benefits of investing in $\mathrm{CO}_{2}$ reductions accrue to the country that incurs the cost of such an investment. As a result, self-interested countries rationally invest too little in $\mathrm{CO}_{2}$ abatement, and instead attempt to free-ride on the hoped-for investments of others. Indeed, "climate change is a public good (bad) par excellence" (Arrow 2007).

The Kyoto process started with a natural approach to breaking the free-rider deadlock: agree on a common commitment. A common commitment helps realign self-interest with the common good by assuring all parties that they will only be required to contribute to the common good if all are required to follow the same commitment rule. This "I will if you will" feature is critical for solving problems of the commons. ${ }^{1}$

1. We will return to this later. For the moment, observe that democracies habitually solve national public-goods problems by voting on a common commitment. Usually this is a commitment to pay a uniform tax with revenues used for public goods, such as parks, highways, education, defense, or cleaning up toxic waste. Voting for a tax is an organized approach to saying "I will adhere to the common commitment if you will.”

\footnotetext{
${ }^{\text {a }}$ University of Maryland, U.S.A.

${ }^{\mathrm{b}}$ University of Cologne, Germany

${ }^{\mathrm{c}}$ Berkeley, U.S.A.
}

Economics of Energy \& Environmental Policy, Vol. 4, No. 2. All rights reserved. 
A common commitment needs to be enforced like any other commitment. Yet the fairness that comes with protection from exploitation offered by a reciprocal common commitment removes one reason to defect. Also, since defecting will weaken the common commitment and hence jeopardize the contributions of others, a well-structured common commitment automatically embodies some enforcement. ${ }^{2}$ Moreover, as we show below, a price commitment reduces risks compared to quantity commitments, and thus reduces the needed size of the enforcement penalty.

In a nutshell, a common commitment facilitates the collective reciprocity which is the only known way of overcoming free riding - the central problem of climate negotiations (Weitzman 2015a). Moreover it is likely a necessary precursor to the implementation of effective enforcement. Yet Kyoto failed to find such a commitment. This failure was no accident. The quantity commitments needed for international cap-and-trade preclude a common commitment. This paper suggests this deficiency of quantity commitments is the motivation underlying the proposals for an international price commitment by Cooper (2004), Nordhaus (2013), Stiglitz (2015), Weitzman (2015a) and ourselves.

\section{* WHY KYOTO FAILED}

Initially, many countries supported a common commitment by all to reduce their emissions by an equal, agreed percentage below their 1990 emission levels. Such a general percentagereduction rule - as opposed to individually pledged percentages - would constitute a common commitment. But many disagreed, and at least ten other formulas were developed and considered. After many failed attempts, the resolve to forge a common commitment was broken and replaced with a resignation to accept individual commitments. Indeed, even before concluding the negotiations, Chairman Estrada allowed parties "to negotiate their own targets," and finally "invited Annex I Parties to submit their revised, final, numbers to the podium" without any restrictions (Depledge 2000, 9192,214 ).

The EU offered a $15 \%$ emission cut with a common commitment, but accepted only $8 \%$ when that failed. ${ }^{3}$ Russia accepted 0\%, Australia and Iceland accepted 8\% and 10\% increases respectively, and the US, a 7\% cut which was not serious. Of course the developing countries accepted nothing, and the EU's 8\% reduction masked cuts that ranged from 30 percent to an increase of $40 \%$. The 95 to 0 rejection by the US Senate was explicitly linked to the fear of free riding although there were other motives as well. The lack of an acceptable common commitment meant there was little check on free riding, but if any common commitment had been forced on the parties, the outcome would have been worse, which is why none was agreed to.

The Kyoto negotiations were right to focus on the search for a common commitment, but what they proved, after more than a year of searching, was that no common quantity commitment can be found. The result was a weak and fragile international cap and the mistaken conclusion that a common commitment is impossible. The mistake was accepting the international-cap-and-trade straight jacket as inevitable.

Interestingly, the Kyoto Protocol also failed to achieve its second goal, equalized prices. International permits were implemented in the form of Assigned Amount Units (AAUs). The

2. In other words, a treaty based on a common commitment is a partially self-enforcing treaty.

3. Kyoto Chairman Estrada personally suggested the target of " $8 \%$ below 1990 emissions" for many countries, and many adopted his suggestion when submitting their final pledges. 
Soviet Bloc's AAUs are referred to as "hot air" in the popular press and, in fact, some AAU trades that took place simply enriched those in Eastern Europe who faced no burden from the Kyoto Protocol. Because trading was seen as inappropriately redistributional and evasive of climate commitments, AAU trading became so controversial that Japan had to publicly deny purchasing AAUs from countries previously in the Soviet Bloc. ${ }^{4}$ And now the U.N. has restricted AAU trading. ${ }^{5}$ As a result, and because of political uncertainties (Edenhofer et al. 2014) and various regulatory interventions (Marcantonini and Ellerman 2014), quantity commitments did not lead to anything like the hoped-for equalization of carbon prices.

Stiglitz (2006b, 2015) has explained why there is no reason to believe anyone will ever come up with a quantity-based emissions rule. The history of the Kyoto negotiations strongly confirms that requiring quantity targets will block any hope of a broad common commitment even without including the developing countries. The US government has now come to the same conclusion. ${ }^{6}$ Without a common commitment, any agreement, if one could be reached, would again be weak and fragile. And it would not produce anything like a uniform price on carbon. Kyoto was a useful experiment, but the world learned the wrong lesson.

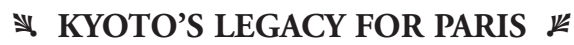

In response to Kyoto's dramatic failure, and then Copenhagen's, the idea of striving for a common global commitment has been abandoned on the way to Paris. Rather, it is hoped now that individually-selected quantity targets will cover the bulk of global emissions with sufficient stringency. Indeed, the plan for Paris is to let every country simply pledge to do whatever it wants. There will be reviews without consequences for hundreds of incomparable proposals (Gollier and Tirole 2015). And if countries fall short of their pledges, there still will be no consequences.

This pledge-and-review approach for Paris is unlikely to work. As the Kyoto Protocol demonstrates, individually adopted targets do not change self-interest, at least not by enough to notice. The reason is that such agreements are not of the "I will if you will" type. In fact, under the Kyoto Protocol, several countries, including the US, Canada, New Zealand, Japan and Russian, have said "We won't" while the others continue to say "We will." So the Protocol is an "I will, even if you won't" agreement. This is an agreement of nations acting altruistically_a coalition of the politically willing. But, as explained by Gollier and Tirole (2015), there is no reason to suppose that altruism can solve the tragedy of the commons. Conditional cooperation in the vein of "I will if you will," on the other hand, provides a strong source of cooperation, as explained by Weitzman (2015a). Indeed, conditional cooperation is the most robust pattern of cooperation seen in laboratory, field and theoretical studies of free-rider situations, and is - unlike unilateral altruism — consistently found to stabilize higher cooperation levels. Numerous studies show that conditionally cooperative strategies can promote

\footnotetext{
4. "Japan is defending itself against criticism that it's exploiting a surplus of Kyoto assigned credits and using 'hot air' to meet emission targets." Bloomberg, 23 July 2009. The importance of high-profile political ramifications caused by unpredictable public transfers between rival countries was anticipated by Cooper (2004), "What US Senator, once s/he understands the full implications of a trading regime, can vote for a procedure which could result in the unconditional transfer of billions of dollars, even tens of billions, to the government of communist China, or to Castro's Cuba, or even to Putin's Russia?"

5. "After tense negotiations, countries decided to restrict how much of this [AAU] surplus can be used for compliance with emission reduction targets." Doha, March 2013, carbonmarketwatch.org/doha-on-aaus-the-future-of-the-phantom-menace. 6. In its 11 March 2013 submission, the US stated, "It is hard to imagine agreement on any formula or criteria for imposition of contributions, as this would get into the most controversial issues."
} 
cooperation levels among selfish players well beyond what is theoretically sustainable. One reason is that conditional cooperation-unlike unilateral altruism-is considered fair (see Bolton and Ockenfels 2000, Cramton et al. 2015, Hauser et al. 2015, Kraft-Todd et al. 2015, and the references therein).

This is why we advocate that negotiations again focus on a common commitment. While a common quantity commitment proved infeasible, we argue that a common price commitment can substantially mitigate many of the problems associated with quantity commitments (see also Stiglitz 2015, Weitzman 2015a). One reason is that there is near-unanimous agreement that each country should commit to the same price, which thus constitutes what Schelling (1960) calls a focal point. Such a common commitment makes possible the type of agreement that changes self-interests for the better: "I will commit to the common price if you will."

The difference between the two commitments, price and quantity, has been overlooked in part because the two can be economically equivalent in a world without uncertainty. A global cap induces a carbon price, and taxing carbon at that price would limit emissions to that cap. But for reaching agreements, the two targets are substantially different. Before exploring that in more depth, it is useful to review why international commitments do not automatically induce specific national policies.

\section{* INTERNATIONAL COMMITMENTS ARE NOT NATIONAL POLICIES $\leftleftarrows$}

Economists sometimes imagine that caps or taxes could be implemented by an international tax-collection agency or by an international cap-and-trade market covering a large majority of each-country's carbon emissions. Such plans assume a dose of top-down regulation that is presently infeasible.

However, a different pair of alternatives requires no such top-down apparatus and would allow countries tremendous flexibility. Under these alternatives, countries simply commit to a set of quantity commitments (regarding carbon permits) or to a price. Either type of commitment could be met by national or regional cap-and-trade markets, fossil-fuel taxes, or any mixture of these along with bonus-malus systems applied to, for example, auto emissions estimated at the time of sale. An example of a mixture is the EU's reliance on a weak capand-trade market and a strong tax on carbon in the form of a tax on oil. Another possibility is cap-and-trade with a floor price. This flexibility should minimize the acrimonious debate over caps and taxes to the extent possible, since all countries could adopt linked cap-and-trade markets under either a global price commitment or a global quantity commitment. And countries also comply with either commitment by using fossil-fuel taxes.

\section{* DEFINING A GLOBAL PRICE COMMITMENT}

A country that commits to the global price only needs to meet the commitment on average. The average carbon price is simply the country's carbon revenues divided by its emissions. The revenue can, of course, come from selling permits under cap-and-trade, from fossil fuel taxes, or from calculations on other pricing-compatible regulation.

There should be some restrictions on how unevenly a country prices its carbon. For example exports should face a price rather close to the global price. (And the same is true under an international cap.) But we will not get into such details. 
Also, our definition leaves a question of how to count pre-existing taxes. There are at least two views on this. For accounting simplicity, all carbon charges would be counted towards compliance. This is the approach that we would prefer for pragmatic reasons. Another view is that this would be true after some base year, say 2015, and the fossil-fuel tax rate in that base year (excluding any taxes imposed for climate reasons) would be subtracted from all future carbon-price measurements. Both approaches are quite simple, and from an implementation point of view, the only difference is that the second approach requires a one-time accounting of fossil-fuel tax revenues at the start. There is no need to untangle taxes by purpose after the initial accounting and even that may be unnecessary. So there is no possibility of gaming the commitment by saying a non-climate tax is for the climate. Going forward all taxes count.

Of course, it is inefficient to credit a new tax to pay for highways as if it were a carbon tax for the climate (Gollier and Tirole 2015). But this is simply the minor inefficiency of not having a perfectly uniform tax-which seems even more out-of-reach with an international cap-and-trade scheme, as we will explain below.

\section{* PRICE VERSUS QUANTITY COMMITMENTS: A COMPARISON}

This paper argues for correcting the flaw that derailed the Kyoto process and for returning to Kyoto's sound fundamental principle: agree on a common commitment that leads to (fairly) uniform carbon pricing. And it proposes to do so in the most straightforward way-by using a global price commitment. Similar views have been expressed by Cooper (2004, 2008), Nordhaus (2013), Weitzman (2014, 2015a), and Cramton and Stoft (2012a, b).

While a single price commitment would be effective and is within reach, as we discuss throughout this paper, it appears impossible to agree on $n$ national quantity commitments. Stiglitz (2015) has made the case that there is no way to achieve a compromise between rich and poor countries regarding quantity commitments, and Weitzman (2015a) too argues that quantities cannot be successfully negotiated. We add that history confirms this. The hope of finding a common quantity commitment was high at the start of the Kyoto treaty but has declined steadily ever since to the point where no one any longer mentions the possibility. Neither is there any discussion of how individual quantity commitments might be negotiated, even in this symposium which raise this as the central topic for discussion. This explains why we will not attempt to refute any arguments that quantity commitments, common or individual, could be successfully negotiated. Rather, we will focus on comparing the two negotiation processes in terms of reciprocity and common commitments.

Importantly, cap-and-trade advocates and tax proponents nearly always agree that a uniform global price is the desired outcome. So unlike quantity, for which there is little if any agreement on the appropriate common commitment rule, there is nearly universal agreement that a common price commitment should be a uniform price commitment (or more precisely a uniform price floor). That is, a uniform price is a natural focal point. This facilitates negotiations about the price commitment (Weitzman 2015a, Schelling 1960).

There is an apparent, but not actual, symmetry between the global cap of Gollier and Tirole (2015) and the global price of our approach. Gollier and Tirole suggest a cap corresponding to $2^{\circ} \mathrm{C}$, which is likely a focal point. Also, as they point out, negotiating a cap avoids the free-rider problem much like negotiating a price. However, there is an important difference. While a global price is a common commitment, a global quantity is only a common 
aspiration. Individual countries can implement the global price, and their commitment to the price is in principle enforceable. But no country can implement the global cap. And an aspiration cannot be enforced.

The practical benefit of a price commitment is that it takes us most of the way to the set of final commitments. It resolves who will do how much for the climate, and of course it can also strive to reach the $2^{\circ} \mathrm{C}$ goal or any other focal climate goal. It leaves only the question of equity transfers to be resolved. This is still a crucial and difficult question (and we will get to it below) but focusing on price helps to disentangle it from the larger question of climate efforts.

Another advantage is that price is an inherently more fair measure of effort intensity than is a Kyoto-style quantity measure. The US has tried to persuade India to commit to a cap in the vicinity of its emissions level, which would have been lower than the per-capita emission of the US in 1880. Not surprisingly, India rejected this idea. Accepting a carbon price would not limit India to any lower emission rate or "intensity rate" than the US, and would even allow India to emit as much or even more per-capita than the United States. A price treats India more equitably and it is at least as efficient as a cap that induces the same carbon emissions.

\section{Monitoring and corruption}

For the two global commitments (as opposed to national policies) there are two main questions that will determine which is best. The first concerns reaching an agreement (discussed above), and the second concerns whether compliance can be verified. Here we discuss verification.

Local monitoring and corruption. Under a commitment to either price or quantity, it is possible for emitters to bribe the carbon-tax collector or the carbon-permit collector (Victor 2001, Tirole 2012). Such corruption will impose an inefficiency on the country but will not disrupt the enforcement of the international commitment, which only requires information of a more aggregate nature. If a power plant dodges its carbon charge, national carbon revenues are reduced. So the country must charge other emitters more to meet its average-price commitment, but the national commitment is still verifiable.

National monitoring and corruption. Emissions should be measured by monitoring the inflow of fossil fuel from extraction and from net imports. Even so, with over 500 coal mines in India and over 18,000 in China, emissions monitoring could be poorly enforced or deliberately distorted. Similarly, under a price commitment, national carbon-pricing revenues could be falsely reported. Although this could be a serious problem in a number of countries, there are several ways to mitigate such problems. There could be monitoring by the IMF, World Bank, IEA or WTO, all of which do some similar monitoring already. Countries receiving green funds could be required to open their national accounting books in order to receive such funds.

Finally, most real carbon pricing will be reflected in visible prices at gas stations, in home heating bills and in retail electricity prices. These prices could be easily monitored. So verification is possible under either commitment, but in a few countries it may require a significant effort. Both commitments would include a requirement to allow verification, and any country that did not cooperate would be considered to be out of compliance and would be sanctioned just as if it had not met its price or quantity commitment. 
International monitoring and corruption. On a global level, the corruption problem is asymmetric. Suppose a local official, on behalf of a kleptocratic ruler, allows a company to under-report emission so that it needs fewer carbon permits. The kleptocrat then sells supposedly-surplus international carbon permits to a perfectly honest country. As Nordhaus (2008) explained, both the government and private company benefit, because this shifts money from honest to corrupt countries. It also crowds out the honest country's abatements.

Conclusion on monitoring. Proponents of international cap-and-trade claim a carbon price cannot be monitored. Yet they claim that cap-and-trade will solve the export-import problem that results from international carbon-price differentials. But as we saw above, equality of nationally-traded permit prices says nothing about the price of carbon emissions from exporters or from anyone else. So the export-import problem can only be solved by monitoring the carbon prices paid by exporters. In other words, a crucial claim of cap-and-trade proponents relies on the assumption that carbon prices can be monitored accurately under the worst of conditions - at the local level, in industries where (unlike at gas stations) the price can be camouflaged, and where there is, perhaps, the strongest incentive for corruption.

Overall, looking at the various arguments in favor and against each commitment type with respect to monitoring and corruption, we tend to agree with Nordhaus (2008) who concludes, "quantity-type systems are much more susceptible to corruption than price-type regimes," and with Cooper (2008) who concludes that a global cap-and-trade system "will unavoidably foster rampant corruption."

\section{Will carbon emission actually be priced?}

The point of international cap-and-trade is usually viewed as imposing on "all $\mathrm{CO}_{2}$ emitters the cost of their damage to the climate." ${ }^{\prime 7}$ The result of this would be an economically efficient reduction in emissions. This efficiency is a central goal of the policy, partly because cost reduction is a great help in making a strong policy sustainable. Environmentalists, however, generally have quite a different goal for cap-and-trade. Their view is that the price doesn't matter but that the cap is a good old-fashioned command-and-control mechanism.

So the question is, will international cap-and-trade induce a uniform and efficient carbon price as economists would like, or will it produced an inefficient mix of national commandand-control policies? Let us look at the Kyoto protocol, which priced international permits and allowed any national policy. This is also specified by Gollier and Tirole, who note that within the OECD countries, there were direct subsidies to green technologies which resulted in implicit carbon prices that range from "less than 0" to "as large as 1,000 €." It is likely that most of this range was spanned within countries that were under the Kyoto Protocol. Gollier and Tirole conclude that such policies demonstrate "the inefficiency of this commandand-control approach."

In other words, in the only test case, the outcome was, by and large, not what economists hoped for but rather the inefficient command-and-control policies. Two conclusions seem evident. International cap-and-trade need not induce much if anything in way of actual carbon pricing, and it may leave the current command-and-control approaches untouched. In other words, international cap-and-trade may not achieve the central objective of its proponents, but rather, the opposite.

7. From sites.google.com/a/chaireeconomieduclimat.org/tse-cec-joint-initiative/some-economic-perspectives, accessed 14 July 2015. 


\section{Committing to a price is less risky}

Quantity targets are favored because they supposedly remove the risk of emission and climate uncertainty and shift that risk to nations in the form of price and cost uncertainty. While their success at limiting climate risk has been dismal, in part due to the uncertainty of the resulting quantity agreements and disagreements, quantity targets do impose risks on the countries that adopt them.

More specifically, accepting a quantity commitment entails risk, because future businessas-usual (BAU) emissions and abatement costs are both highly uncertain. Suppose that a country expects BAU emissions of $100 \mathrm{Mt}$ and considers two commitments: (1) a quantity reduction to $90 \mathrm{Mt}$ and (2) a price of $\$ 20 / \mathrm{t}$. Assume these are equivalent (they both cause the same price and same emission quantity). Furthermore, assume that the global carbon price will be $\$ 20 /$ t.

Now suppose, that the country's BAU emissions turn out to be $110 \mathrm{Mt}$ (10 Mt higher than expected). Under the quantity commitment, the $\$ 20 / \mathrm{t}$ global price will reduce emissions $10 \%$ to $99 \mathrm{Mt}$. But the country will only have been issued $90 \mathrm{Mt}$ of permits, so it will need to buy $9 \mathrm{Mt}$ of permits on the world market for a cost of $\$ 180 \mathrm{M}$. Under a price commitment, the country simply sets its carbon price to $\$ 20 / \mathrm{t}$ as if nothing had changed.

Even though the price-commitment policy specifies that countries keep all of the carbon revenues from pricing carbon, there is still a social cost. To find that cost, note that the more that is abated, the greater the cost per ton abated, with the per-unit cost starting at $\$ 0 /$ ton and reaching a maximum of $\$ \mathrm{P} /$ ton. So the standard estimate of the cost of abatement, $\mathrm{A}$, under carbon price, $P$, is $A \times P / 2$, or in this case $11 \mathrm{Mt} \times(\$ 20 / \mathrm{t}) / 2$, which equals $\$ 110 \mathrm{M}$. This cost occurs under either policy because the global price of $\$ 20$ causes $11 \mathrm{Mt}$ of abatement in both cases.

Hence the total cost under the quantity commitment is $\$ 180 \mathrm{M}+\$ 110 \mathrm{M}=\$ 290 \mathrm{M}$. That's 2.6 times as much as the $\$ 110 \mathrm{M}$ cost under the price commitment. But some cost was expected to occur under the expected BAU emission of $100 \mathrm{Mt}$. That expected cost was $10 \mathrm{M} \times \$ 20 / 2$, or $\$ 100 \mathrm{M}$. So the unexpected cost under the quantity policy is $\$ 290 \mathrm{M}$ - $\$ 100 \mathrm{M}=\$ 190 \mathrm{M}$, while the unexpected cost under the price commitment is $\$ 110 \mathrm{M}$ - $\$ 100 \mathrm{M}=\$ 10 \mathrm{M}$. The financial risk from a possible $10 \%$ shock to BAU emissions in this example is 19 times greater with caps than under a price commitment. ${ }^{8}$

This example does not exaggerate the risks of quantity commitments. In 2000, the US DOE's International Energy Outlook predicted China's 2010 emissions would be $1.5 \mathrm{Gt}$, but in the event, emissions were over $7 \mathrm{Gt}$-nearly a $400 \%$ error rather than the $10 \%$ error assumed in the above example. And quantity targets generally have been set 10 to 15 years in advance. Moreover quantity errors can have a high political sensitivity. If China had committed to a cap in 2000 equal to its expected BAU emissions (not reduced by any cooperative climate efforts) it would have been purchasing over 5 billion tons of permits annually by 2010 from, perhaps the US and the EU. This would have likely cause a dramatic permit shortage and high carbon prices, but even at $\$ 20$ /ton this comes to $\$ 100$ billion per year in highly visible transfers to foreign countries. If China had made anything like the quantity commitments desired of it by cap-and-trade advocates at that time, quantity risks would have likely destroyed

8. Based on our example, Weitzman (2015b) has recently shown in a rigorous and general model, that under uncertainty, internationally-tradable permits expose a country to unambiguously greater risk than the imposition of a uniform carbon price whose tax proceeds are domestically retained. 
that international quantity commitment and any associated cap-and-trade treaty. China was right to reject such quantity commitments.

\section{Enforcement}

A major advantage of monitoring and enforcement of a price commitment is that it is an annual rather than a once-in-15-year event, like the Kyoto Protocol or like China's recent commitment to cap emissions in 2030. This creates free-riding incentives and diffuses responsibilities among successive governments within countries, and makes it difficult to repair non-compliance. Annual price commitments have the advantage that cheating can be quickly detected, and can be quickly corrected, because full compliance can be achieved simply by increasing the carbon charge. Indeed, frequent monitoring is known to be one of the most critical aspects of self-enforcing cooperation (Ostrom 1990).

Gollier and Tirole (2015) propose a fix for this problem: "countries will have to match pollution and permits at the end of the year to avoid creating unfulfilled climatic debt." Unfortunately, this proposal blocks banking and borrowing of permits, the standard method of mitigating the volatility of permit prices. Such price volatility is likely to be unpopular with investors and the public.?

Successful enforcement is one key to successful cooperation (Nordhaus 2015). We have argued before that cooperation based on a common commitment is relatively easy to enforce, because the common commitment enables a reciprocal relationship, which is known to promote cooperation. Here we argue that a common price commitment facilitates enforcement compared to a quantity commitment. One reason is that a price commitment is continuously monitored and thus more easily enforceable (see above). Another reason is that it reduces risks (as discussed above). Risks can produce strong incentives to leave or avoid a quantity commitment. Without such strong negative incentives, the needed size of the enforcement penalty is reduced. Finally, price commitments reduce the required size of equity transfers (as we describe below), which also reduces the needed size of the enforcement penalty.

There are various complementary mechanisms that can further ease the enforcement of price commitments. For instance, efficient performance, which we borrow from modern electricity markets where deviations from plans are settled at the market price for carbon revenues. In other words a country that exceeds its commitment can sell its excess performance to a country that falls short. This guarantees that plans are met in aggregate and yet gives countries the flexibility to easily and efficiently react in an uncertain environment. Efficient resolution of deviations from plans greatly reduces risks, facilitates performance, and encourages participation.

\section{The waiting game}

Gollier and Tirole (2015) explain that negotiations that are currently ineffective but are likely to eventually result in individual pledges contribute to what they call the "waiting game." The result of this game is that present behavior, while waiting for an agreement on individual commitments, can be even worse than the outcome of the non-cooperative Nash equilibrium of the public goods game-worse than without any thought of cooperation.

9. In that respect, the first trading period in the context of the EU-ETS provides a good lesson of undesired price effects when banking and borrowing is not allowed. 
The problem does not arise if a common commitment is expected to be the eventual outcome. Yet if individual climate commitments are expected, it pays countries to jockey now for position in the final round of commitments. For example, if it is expected that commitments will be made relative to 2020 emissions or some future BAU emissions, then it pays to not take easy actions to reduce emissions before 2020.

But if the eventual commitment will be a common price, then having higher emissions in 2020 will simply mean more emissions will be taxed at the global price. This confers no advantage on the recalcitrant country. That is, deciding now to agree on a common price ends the waiting game now, even though there is still a wait for the actual agreement.

\section{* THE ROLE OF THE GREEN FUND AND EQUITY TRANSFERS}

\section{Equity transfers are less expensive with price commitments}

Agreeing on price as the indicator of global action opens the door to a common commitment. But poorer countries like India will feel that they should receive significant help with it. Fortunately, this is relatively inexpensive. Since India's carbon-pricing revenues would stay in India, pricing India's two billion tons of emissions at $\$ 20$ per ton will have a net cost to India of only about $\$ 2 \mathrm{~B}$ if emissions were reduced $10 \%$ - far less than the planned $\$ 100$ B per year Green Climate Fund. This is not to suggest that India should be given an exception to the common commitment. Rather, the common commitment should include a green-fund formula for providing assistance from richer, high-emission countries to poorer, low-emission countries. In this way, the common pricing commitment would respect the UN's principle of "common but differentiated responsibilities."

Equity transfers need not be as high with price commitments, because risk is lower. As seen in the above example of price and quantity risk, if a country expects a $\$ 100 \mathrm{M}$ cost of abatement, but there is a risk that its BAU emissions will be unexpectedly high by $10 \%$, this would add $\$ 190 \mathrm{M}$ in the case of a quantity commitment and only $\$ 10 \mathrm{M}$ in the case of a price commitment. If the country demands that this risk be covered by equity transfers, these will need to be $\$ 180 \mathrm{M}$ larger in the case of a quantity commitment. Politically it seems difficult for a poor country to risk having its equity transfer obliterated by a miscalculation of future BAU emissions.

\section{Choosing a green fund formula}

By committing to a uniform global price, we have confined the differentiated-responsibilities problem to the green-fund formula. This makes possible a natural, and less-divisive, principle for national differentiation. The new design principle is to choose the green-fund formula that maximizes global emissions abatement.

This suggests a two-step design: first select the green-fund formula, then choose the common price. This is similar to many political processes in which it is common to specify the payment and benefit structure before deciding how much to spend on a program, say a school system. If voters are pleased with the payment-benefit structure they will be generous in voting for a strong program. If they are displeased they will be less generous. This arrangement gives those designing the payment-benefit structure, in this case the green-fund structure, a strong incentive to design the structure to please all of those whose support is needed. It also allows the funders to have peace of mind when the funders delegate authority to those 
negotiating the structure-first because they know that they can reject or minimize the proposed structure if it is not to their liking, and second because they know the negotiator/ designers will be well aware of this.

Compare this to the cap-and-trade alternative, which is also a two-step approach. First the global cap $Q$ is selected and then the permit allocations $\left\{A_{i}\right\}$ are negotiated. But, as noted above, $Q$ is an aspiration and not a commitment, so all of the work of solving both the climate-effort problem and the equity-transfer problem are bundled into the single step of negotiating $\left\{A_{j}\right\}$. In contrast the two-step approach of pricing breaks the problem in twochoosing climate effort $(P)$ and negotiating equity transfers $\left\{G_{i}\right\}$ - this simplifies both negotiations. Then it links the two halves so that the availability of the step-two price decision provides good incentives for, and confidence in, the green-fund design process. And the greenfund design is properly focussed on making the price negotiation successful. This is why the " $\left\{G_{i}\right\}$ then $P$ " negotiation process can outperform the " $Q$ then $\left\{A_{i}\right\}$ " process.

We now describe, for the sake of concreteness, a possible pair of negotiating procedures, beginning with the step-two price negotiation. To set the price, countries pledge their highest acceptable global price target, taking the step-one green-fund formula into account. Then the highest price target acceptable to, say, $70 \%$ of the countries (emissions-weighted), determines the global price commitment. ${ }^{10}$ Only countries that have pledged at least that price would sign the global-pricing agreement and participate in the green fund. ${ }^{11}$ (This "club" could then implement enforcement that could induce additional members to join; see Stiglitz 2015.)

Before describing step-one, the green-fund negotiation, we note that, as pointed out by Gollier and Tirole (2015), it is an n-dimensional negotiation and hence difficult. As with the climate-effort negotiations, a common formula is needed, but here we are not lucky enough to have something as simple and well-agreed-upon as a uniform price. Nonetheless, it pays to look for an equity formula that is focal and has a single parameter that can differentiate responsibilities to the extent required. Of course in reality no simple formula will be sufficient. However, this example will serve to illustrate the value of looking for a common-commitment formula, even if the actual one needs to weight multiple relevant variables.

The formula that we propose as most simple and focal for green-fund transfers is to make transfers proportional to a country's excess emissions. These are defined as emissions that are in excess of what the country would emit if it had world-average per-capita emissions. Countries pay into the green fund in proportion their excess emissions and receive payments from the green fund in proportion to their negative excess emissions.

There seems little doubt that this formula would work if accepted, because perfection is not required. But it would likely not achieve as high a price as a more detailed and thoughtfully designed formula. The formula should be judged by how high a price results from its use in the stage-two voting process.

The excess-emissions formula must also include a generosity parameter, $G$, that determines its strength-how many dollars per ton of excess emissions will be transferred. If the greenfund formula is too generous, rich countries will hold down the global price to reduce greenfund payments. And if the formula is too miserly, poor countries will hold down the carbon price to reduce the burden of carbon pricing. Only a compromise on generosity will lead to

10. The higher the coverage of global emissions, the lower the price that will be agreed to by all the countries that must be included to achieve that coverage.

11. Countries may also agree on a price path. In any case, this initial agreement would be updated periodically with the intention of increasing its coverage and strength, and of reflecting the improving estimates of costs and benefits of climate change. 
the highest agreed global carbon price and maximize abatement ambition. Hence, the objective of maximizing ambition leads naturally to a reasonably fair compromise on differentiation of responsibilities.

To assure that the generosity of the green-fund formula is set objectively to maximize climate ambition, it will be best to rely on countries that have the least stake in green-fund payments. Such countries will base their recommendations on climate considerations rather than on green-fund considerations. Within such a group, the median (not the average) opinion should determine the outcome. This prevents any one country from having too much influence (Cramton and Stoft 2012a, b).

When proposing individual commitments, the US argues (2013) that it is "hard to imagine that Parties would be willing to have other Parties dictate their contributions." But the above illustrative agreement shows the US argument is irrelevant. Under such an agreement no country will ever be asked to commit to a price higher than it nominates voluntarily with full knowledge of the generosity of the green fund. Nothing is "dictated" by other Parties. But in spite of the completely voluntary nature of this treaty, the resulting agreement captures the "I will if you will" effect of a common commitment that modifies self-interest within the agreeing group. Hence, each country's self-interest in naming a high price will be increased dramatically relative to the individual commitments the US is proposing.

\section{Why opaqueness is not an argument for quantity commitments}

Some observers argue that a green fund is too transparent to be politically acceptable, and that a supposed lack of transparency is a major advantage of cap-and-trade. However, the capand-trade programs often referred to are domestic, and are opaque for a different reason. Their transfers are not in the form of traceable money. Companies get paid mainly by raising commodity prices by an amount that is hard to measure and that most people cannot comprehend. On the other hand, international purchases of AAU's - the real standard of comparison-have been extremely controversial, as we described in our introduction. Indeed, we find it difficult to believe that large cross-border money transfers through perfectly transparent markets would not catch the public's attention. It seems even more likely that the transfer will become obvious at an earlier stage. To give India a large transfer, India must receive a cap that is far above its BAU emissions level. This part of the transfer will be highly visible and past comments have shown that environmentalists will find this highly objectionable. It will also make it impossible to explain to the US public why the US is giving a multibillion dollar climate transfer to a country that is required to do less than nothing.

That said, even if the supposed opaqueness of permit transfers is something worth taking advantage of, this might be possible under a price commitment without incurring the political risk premiums associated with quantity commitments. For example, instead of the US government paying India $\$ 100 \mathrm{M}$, it could allow US businesses to purchase offsets from the Indian government at the global price of carbon, and India could be issued a package of say 5 million one ton permits. While these would be just as visible as permits under cap-andtrade, they would not cause the financial risks of cap-and-trade.

\section{* CONCLUSIONS}

Despite much rhetoric, there is almost no hope that the Paris negotiations, if based on individual pledges, can solve the climate dilemma. Rather, to address the dilemma, we agree with 
all experts in this symposium that a common commitment is necessary. In this piece, we reiterate Weitzman's plea that price and quantity commitments be compared on a level playing field. This seems eminently reasonable since quantity commitments have had the field to themselves for over 20 years, and failed repeatedly. Quantity commitments have been favored partly because of the misperception that caps provide stronger incentives and more certainty than a price, together with an incorrect analogy between an easily-enforced domestic cap and unenforced international caps. Yet, for reasons that we and other contributors to this symposium explain, a price commitment is likely a much more promising basis for a common commitment; it is a fair focal point, reduces risks, is easier to enforce, and is consistent with climate policies already in place. Indeed, one beauty of a carbon price commitment is that it will not interfere with the current, dispersed cap-and-trade experiments, thereby leaving the door open to a future rehabilitation of caps, while keeping alive the fundamental idea of using price.

Promoting cooperation in international climate negotiations is the crux of the climate problem. We hope our paper, along with the other contributions in the symposium, will provide guidance to those negotiating the necessary global agreements. After over 20 years of failure, surely it is worth attempting a fresh approach, one that is guided by insights from the science of cooperation.

\section{* ACKNOWLEDGMENTS}

Financial support of the German Research Foundation (DFG) through the Research Unit "Design \& Behavior" (FOR 1371) is gratefully acknowledged. Ockenfels thanks the Economics Department at Stanford University for their generous hospitality. We thank Ken Arrow, Ottmar Edenhofer, Larry Goulder, Charlie Kolstad, Ulrike Kornek, and Massimo Tavoni for helpful discussions and the Stanford Institute for Economic Policy Research for providing a productive setting for discussions.

\section{References}

Arrow, K. (2007). “Global Climate Change: A Challenge to Policy," The Economists' Voice. http://dx.doi.org/ $10.2202 / 1553-3832.1270$.

Bolton, G.E., A. Ockenfels (2000). "ERC—A Theory of Equity, Reciprocity and Competition." American Economic Review, 90(1): 166-193.

Cooper, R. (2004). “A Global Carbon Tax?” Council on Foreign Relations, Commissioned Briefing Notes for the CIGI/CFGS L20 Project.

Cooper, R.N. (2008). "The Case for Charges on Greenhouse Gas Emissions.” Discussion Paper 08-10, Harvard Project on International Climate Agreements, Belfer Center for Science and International Affairs, Harvard Kennedy School.

Cramton, P., D. MacKay, A. Ockenfels, and S. Stoft (2015). "Solving the Climate Dilemma."

Cramton, P. and S. Stoft (2012a). "Global Climate Games: How Pricing and a Green Fund Foster Cooperation," Economics of Energy \& Environmental Policy, 1(2). http://dx.doi.org/10.5547/2160-5890.1.2.9.

Cramton, P. and S. Stoft (2012b). "How to Fix the Inefficiency of Global Cap and Trade," The Economists' Voice. http://dx.doi.org/10.1515/1553-3832.1787.

Depledge, J. (2000). "The Origins of the Kyoto Protocol," prepared under contract to the UNFCCC, FCCC/ $\mathrm{TP} / 2000 / 2$.

Dion, S. and E. Laurent (2012). "From Rio to Rio: A Global Carbon Price Signal to Escape the Great climate Inconsistency," Working papers OFCE, 2012-16, May.

Fudenberg, D. and J. Tirole (1991). Game Theory, Cambridge, MA: MIT Press. 
Gollier, C. and J. Tirole (2015). "Negotiating Effective Institutions Against Climate Change,” Economics of Energy \& Environmental Policy, 4(2): 5-28.

Hauser, O.P., D.G. Rand, A. Peysakhovich, and M.A. Nowak (2014). "Cooperating with the Future," Nature (doi:10.1038/nature13530). http://dx.doi.org/10.1038/nature13530.

Kraft-Todd, G.T., E. Yoeli, S.P. Bhanot, and D.G. Rand (2015). "Promoting Cooperation in the Field," Current Opinion in Behavioral Sciences, 3:96-101. http://dx.doi.org/10.1016/j.cobeha.2015.02.006.

Kosfeld, M., A. Okada, and A. Riedl (2009). "Institution Formation in Public Goods Games," American Economic Review, 99, 1335-1355. http://dx.doi.org/10.1257/aer.99.4.1335.

Nordhaus, W. (2008). A Question of Balance, Yale University Press.

Nordhaus, W. (2013). The Climate Casino, Yale University Press.

Nordhaus, W. (2015). "Climate Clubs: Overcoming Free-riding in International Climate Policy," American Economic Review, 105:4. http://dx.doi.org/10.1257/aer.15000001.

Ostrom, E. (1990). Governing the Commons: The Evolution of Institutions for Collective Action, Cambridge University Press. http://dx.doi.org/10.1017/CBO9780511807763.

Schelling, T.C. (1960). The Strategy of Conflict. Cambridge, MA: Harvard University Press.

Stiglitz, J.E. (2006a). “A New Agenda for Global Warming,” The Economists'Voice, 3:7. http://dx.doi.org/10.2202/ 1553-3832.1210.

Stiglitz, J.E. (2006b). “Saving the Planet,” Making Globalization Work, chapter 6.

Stiglitz, J.E. (2010). "Overcoming the Copenhagen Failure,” Project Syndicate.

Stiglitz, J.E. (2015). "Overcoming the Copenhagen Failure with Flexible Commitments," Economics of Energy \& Environmental Policy, 4(2): 29-36.

Stoft, S. (2009). "Flexible Global Carbon Pricing: A Backward-Compatible Upgrade for the Kyoto Protocol," European University Institute Working Paper No. RSCAS 2009/35.

Tirole, J. (2012). "Some Political Economy of Global Warming," Economics of Energy and Environmental Policy, 1, 121-132. http://dx.doi.org/10.5547/2160-5890.1.1.10.

Victor, D. (2001). The Collapse of the Kyoto Protocol and the Struggle to Slow Global Warming, Princeton.

Weitzman, M. (2014). "Can Negotiating a Uniform Carbon Price Help to Internalize the Global Warming Externality?" Journal of the Association of Environmental and Resource Economists, 1(1/2): 29-49. http:// dx.doi.org/10.1086/676039.

Weitzman, M. (2015a). “Internalizing the Climate Externality: Can a Uniform Price Commitment Help?” Economics of Energy \& Environmental Policy, 4(2): 37-50.

Weitzman, M. (2015b). "Internationally-Tradable Permits are Riskier for a Country Than an Internally-Imposed Carbon Price,” Harvard University. 